\title{
Cruzando fronteiras regionais: repensando a história comparada da educação em âmbito nacional
}

\author{
ROSA FÁTIMA DE SOUZA \\ Universidade Estadual Paulista, Araraquara, SP, Brasil
}

\section{RESUMO}

Este texto objetiva analisar algumas questões problemáticas envolvidas nos estudos de história comparada da educação no Brasil, em âmbito nacional. Discute as tensões presentes nos recortes espaciais estabelecidos para a investigação comparada e algumas abordagens e métodos norteadores da comparação histórica. As tensões entre o regional, o estadual e o nacional são discutidas considerando, por um lado, a perspectiva política, isto é, as iniciativas dos poderes públicos em relação à educação, e, por outro, as representações sobre a identidade nacional presentes no pensamento social brasileiro. Em relação às abordagens teóricas, o texto examina as contribuições e os limites da perspectiva sócio-histórica no campo da educação comparada e das histórias conectadas e história cruzada no campo da história comparada. A reflexão busca apontar os desafios e as possibilidades de estudos dessa natureza compreendendo a comparação como instrumental importante para o confronto tanto da produção quanto das realidades educacionais diversas e diferenciadas do país.

\section{PALAVRAS-CHAVE}

história comparada da educação; história da educação; história comparada em âmbito nacional; comparação. 


\title{
CROSSING REGIONAL BORDERS: RETHINKING THE COMPARATIVE HISTORY OF NATIONAL EDUCATION
}

\begin{abstract}
This text analyzes problematic questions entangled in the studies of comparative history of education in Brazil. It discusses the tensions present at the spatial selection chosen for this comparative investigation and some approaches and methods guiding the historical comparison. The strains among regional, state and national level are treated considering the initiatives of the public power towards education and the representations of the national identity present in the Brazilian social thinking. Regarding the theoretical background, the text examines the contributions and limits of the social-historical perspective in the field of comparative education and the connected histories crossed on the field of comparative history. The reflection aims to point to the challenges and possibilities of studies of this nature understanding the comparison as an important tool for the confrontation of research production as well as the diverse and different educational realities in the country.

KEYWORDS

comparative history of education; history of education; comparative history of national education; comparison.
\end{abstract}

\section{CRUZANDO FRONTERAS REGIONALES: REPENSANDO LA HISTORIA COMPARADA DE LA EDUCACIÓN EN EL ÁMBITO NACIONAL}

\section{RESUMEN}

Este texto analiza temas problemáticos incluidos en los estudios de la historia comparada de la educación en Brasil a nivel nacional. Discute los intereses presentes entre lo regional, estatal y nacional considerando las iniciativas de los poderes públicos en relación a la educación y las representaciones sobre la identidad nacional presente en el pensamiento social de Brasil. Teóricamente el texto examina las contribuciones y límites de la perspectiva socio historica en el campo de la educación comparada y la historia cruzada en el campo de la historia comparada. Esta reflexión busca apuntar los desafíos y posibilidades de los estudios de esa naturaleza comprendiendo la comparación como instrumento importante para el embate de la producción de pesquisas de las diferentes y diversas realidades del país.

\section{PALABRAS CLAVE}

historia comparada de la educación; historia de la educación; historia comparada en el ámbito nacional; comparación. 
Comparar países. A nação tem sido a unidade predominante nos estudos comparativos em educação. Qual o sentido, portanto, do investimento na comparação entre regiões de um mesmo país? É conveniente adotar os mesmos referenciais teórico-metodológicos utilizados na comparação entre nações para a comparação em âmbito nacional? Como lidar, do ponto de vista histórico, com as tensões entre o regional, o estadual e o nacional presentes na configuração da educação brasileira? Refletir sobre esses questionamentos torna-se tarefa incontornável no debate atual sobre as relações entre história da educação e comparação. ${ }^{1}$

Há mais de uma década, em conferência apresentada no I Congresso Brasileiro de História da Educação, realizado no Rio de Janeiro em 2000, Clarice Nunes reconhecia a ausência, no Brasil, de uma discussão aprofundada sobre o tema, assinalando a necessidade de confronto entre regiões do país e entre diferentes países e questionando por que pesquisadores da área resistiam à comparação, não se deixando seduzir por essa possibilidade de pesquisa (Nunes, 2001).

Muito embora tenha crescido no país o número de pesquisas históricas comparando aspectos educacionais entre o Brasil e outros países, esse conjunto de estudos ainda é relativamente pequeno considerando a produção da área. ${ }^{2}$ Já a comparação entre as regiões brasileiras ganhou um impulso relativo nos últimos anos. ${ }^{3}$ Não obstante, a imprescindibilidade de estudos dessa natureza inscreve-se na própria constituição histórica do sistema educacional no Brasil, caracterizado pela descentralização do ensino elementar e secundário e pela centralização do ensino superior. $\mathrm{O}$ fato é demasiadamente conhecido. $\mathrm{O}$ ato adicional de 1834 (lei n. 16, de 12 de agosto de 1834) estabeleceu como uma das competências das assembleias legislativas provinciais legislar sobre instrução pública e estabelecimentos próprios

1 Este texto sintetiza reflexões de natureza teórico-metodológicas desenvolvidas no âmbito do projeto temático "História da escola primária no Brasil: investigações comparadas (1930-1961)", apoiado pelo Conselho Nacional de Desenvolvimento Científico e Tecnológico (CNPq). Agradeço as preciosas contribuições da equipe do referido projeto de pesquisa, composta por trinta e seis pesquisadores pertencentes a diferentes universidades do país, com quem tenho compartilhado instigantes discussões sobre os desafios da pesquisa histórica comparada da educação. Este trabalho foi apresentado na 36ª Reunião Nacional da Associação Nacional de Pós-Graduação e Pesquisa em Educação (ANPEd), em 2013, no Grupo de Trabalho "História da Ėducação"(GT02).

2 Um número crescente de textos e livros abordando estudos históricos da educação em perspectiva comparada foi publicado no Brasil nos últimos anos. Entre as várias pesquisas realizadas comparando nações, embora com diferentes enfoques, citamos: Bontempi Jr. (2000); Carvalho e Pintassilgo (2011); Souza e Martínez (2009); Toledo e Carvalho (2011); Vidal e Ascolani (2009); Vidal e Gvirtz (1998); Warde (2000). Alguns livros têm reunido estudos de diferentes países visando propiciar a comparação. Ver: Araújo (2009); Gondra e Silva (2011); Werle (2007).

3 Como exemplo dessa tendência, podem ser assinalados dois projetos de abrangência nacional financiados pelo CNPq: o projeto "Por uma teoria e uma história da escola primária no Brasil: investigações comparadas sobre a escola graduada (1870-1950)", desenvolvido no período de janeiro de 2008 a junho de 2010 (primeira etapa) e o projeto "História da escola primária no Brasil: investigações comparadas", concluído em dezembro de 2014. Resultados desses dois projetos podem ser encontrados nos seguintes livros: Araújo, Souza e Pinto (2012); Castro (2011); Souza, Silva e Sá (2013). 
para promovê-la, com exceção das faculdades de medicina, cursos jurídicos e academias existentes. Em decorrência, ficava estabelecida a dualidade de competências do poder público - o governo geral ficaria responsável pelo ensino superior e o governo provincial pelo ensino primário e secundário.

A Constituição Republicana de 1891 manteve, pelo federalismo, a descentralização da educação, desobrigando a União da responsabilidade pelo ensino elementar e secundário, enquanto reiterava, no âmbito nacional, sua competência em relação ao ensino superior.

Dessa maneira, cada estado organizou o seu sistema próprio de instrução pública investindo de forma diferenciada na modernização e expansão do ensino primário, técnico-profissional e secundário. Consequentemente, as diferenças regionais/estaduais tornaram-se a característica marcante da educação no país. Assim, a desigualdade regional verificada continuamente nos índices de analfabetismo, no atendimento à demanda pela educação elementar e média tornou-se constitutiva da dinâmica do federalismo brasileiro assentado em diferenças sociais, econômicas e culturais.

Mas a comparação entre os estados/regiões encontra justificativa também na produção historiográfica em educação. Até os anos 1980, essa produção foi informada pelas "macroabordagens" tomando os polos dinâmicos da economia como referência para uma história nacional da educação. A renovação do campo ocorrida nas últimas décadas inverteu essa tendência dando primazia a novos objetos e abordagens e a recortes espaciais determinados no âmbito dos estados, regiões e localidades. $\mathrm{O}$ crescimento dos cursos de pós-graduação em educação instalados nas mais diferentes regiões do país reforçou essa aproximação dos pesquisadores com temas de interesse regional/estadual e com a identificação e levantamento de fontes de pesquisa nos arquivos públicos estaduais e arquivos escolares.

Porém, como apontam vários balanços da produção da área realizados nos últimos anos (Alves, 2005; Galvão et al., 2008; Vidal et al. 2005; Xavier, 2001), essa produção marcadamente regional tem acarretado a fragmentação dos estudos e requerido o diálogo maior entre as histórias regionais. ${ }^{4}$

Este texto objetiva analisar algumas questões problemáticas implicadas nos estudos de história comparada da educação no Brasil, em âmbito nacional. Discute as tensões presentes nos recortes espaciais estabelecidos para a investigação comparada e algumas abordagens e métodos norteadores da comparação histórica. A reflexão busca apontar os desafios e as possibilidades de estudos dessa natureza compreendendo a comparação como instrumental importante para o confronto tanto da produção quanto das realidades educacionais diversas e diferenciadas do país.

4 Vários pesquisadores têm assinalado a importância dos estudos comparados da educação em perspectiva histórica. Ver, entre outros: Catani (2000, 2007); Nunes (1998, 2001); Saviani (2001). 


\section{AS TENSÕES ENTRE O REGIONAL, O ESTADUAL E O NACIONAL}

A comparação interna ao país requer uma discussão sobre recortes espaciais e clivagens territoriais, além de dado entendimento sobre questões candentes nas ciências sociais e na história, como as relações entre o particular e o geral, o local e o global, as micro e as macroabordagens no conhecimento histórico das sociedades. Exige também considerar a constituição dos sistemas estaduais de ensino, isto é, as especificidades do desenvolvimento da educação nos diferentes estados e o modo como vêm sendo produzidas as interpretações sobre essas especificidades e diferenças.

Se é possível reconhecer a existência no Brasil de uma geografia regional dos novos relatos históricos, como afirma Costa Rico (2006) para o caso espanhol, cabe interrogar sobre como se inter-relaciona a história da educação das diferentes regiões brasileiras. ${ }^{5}$

Uma primeira dificuldade advém da imprecisão no uso dos termos. Muitas vezes utilizamos o termo região no mesmo sentido de estado, outras vezes em um sentido particular ou remetendo à divisão administrativa - geográfica do país. A noção de região é problemática até mesmo no campo da geografia. De forma genérica, ela contém a ideia de parte de um todo, mas o termo remete também ao sentido de unidade administrativa e de identidade espaço-cultural (Lencioni, 2003). A esse respeito, Paulo César Gomes (2008) assinala que, desde a sua origem na Antiguidade clássica, o conceito de região pressupõe o fundamento político de gestão de um território e o problema da identidade, ou seja, "a questão da relação entre a centralização, a uniformização administrativa e a diversidade espacial, diversidade física, cultural, econômica e política, sobre a qual esse poder centralizado deve ser exercido" (idem, p. 52). Pressupõe, portanto, questões de identidade e poder. O recorte regional é muitas vezes assumido como um dado sem questionamento, não problematizado como construção histórica. Por isso, é importante reconceituar a região considerando as fronteiras legais e as espacialidades superpostas e conexas de modo que compreenda a educação em suas diversas especificidades e configurações.

Como acertadamente assinala Maria do Carmo Campello Souza (2006), as populações estão situadas geograficamente e as regiões detêm o caráter de enclaves culturais, isto é, elas possuem tradições e valores que perduram ao longo do tempo. No Brasil, as relações de pertencimento e de identidade regional são múltiplas e ultrapassam a divisão territorial e regional estabelecida pelo Estado com vistas ao levantamento e divulgação de dados estatísticos. Norte, Nordeste, Centro-Oeste, Sudeste e Sul são criações políticas alicerçadas no pensamento geográfico brasileiro, ainda que propiciem representações sobre pertencimentos regionais. Significa dizer

5 Nos últimos anos, foram publicadas algumas coletâneas e dossiês reunindo estudos históricos sobre a educação de diferentes estados brasileiros ensejando a comparação. Ver, a título de exemplo: Araújo, Freitas e Lopes (2008); Bittencourt (2004); Miguel, Vidal e Araújo (2011); Vidal (2006). Exemplo de estudo histórico sobre educação em perspectiva comparada entre estados brasileiros encontra-se em Neves (2009). 
que há regiões não coincidentes com as fronteiras políticas juridicamente definidas. Mas a questão é saber de que maneira as múltiplas identificações regionais se relacionam ou interferem na realidade educacional.

Os estados da federação sobressaem como unidades fundamentais na delimitação da comparação interna no país em virtude da relevância das políticas dos governos estaduais para a educação pública na conformação dos sistemas estaduais de ensino. Assim, é possível compreender algumas realidades educacionais, como a difusão do ensino primário, secundário e técnico-profissional, a institucionalização da escola, a formação e profissionalização do magistério primário, a erradicação gradativa do analfabetismo, a inovação dos métodos e processos de ensino, os discursos de exaltação do valor da escola pública para a promoção do progresso e modernização do Estado e para a constituição da cidadania e da nacionalidade.

Todavia, não se devem assumir os estados como unidades homogêneas sob o risco de dissolver as clivagens regionais existentes no interior deles ou para além deles. Outro problema, para ficar somente no nível das políticas educacionais, é o papel dos municípios em relação ao ensino. Ainda pouco investigada na história da educação no Brasil, a ação dos municípios na difusão do ensino primário, normal e secundário, na alfabetização de adultos e na educação infantil, põe em questão especificidades quase sempre ignoradas pela historiografia da educação. Não se deve esquecer, ainda, o peso do regionalismo na evolução política do Brasil e o modo pelo qual esteve continuamente em debate no país, considerado ideário educacional e entendido como adaptação da escola ao meio.

Sejam quais forem as unidades espaciais elegidas para a comparação histórica, o pesquisador encontrará dificuldades teórico-metodológicas de operar com a homogeneização de processos heterogêneos e de relacionar especificidades que guardam interfaces em diferentes planos temporais e espaciais (região, estado, município, nação, mundo).

Outro problema de não menor importância é o da nação como recorte espacial. Para além da constituição jurídica, territorial e política do Brasil, o comparatista deve levar em conta as tensões entre políticas estaduais e nacionais e as representações erigidas sobre a nação.

Cynthia Veiga (2011) tem razão ao afirmar a ausência, no início da República, de um projeto nacional de educação voltado para o favorecimento da democracia. A partir de 1930, com a centralização política, verifica-se a intervenção cada vez maior do governo federal na educação do país. Nessa direção podem ser apontados inúmeros elementos indicadores dessa centralização, como as leis orgânicas do ensino industrial, secundário, comercial, primário, normal e agrícola, a criação do Fundo Nacional do Ensino Primário, a atuação do Instituto Nacional de Estudos Pedagógicos (INEP) em relação ao ensino rural, as leis de equivalência do ensino secundário até a promulgação da Lei de Diretrizes e Bases, em 1961. Esses, entre outros exemplos, indicam que a comparação entre regiões e/ou estados do país não pode perder de vista as inter-relações entre as políticas estaduais e as políticas nacionais de educação. Outros elementos a serem considerados são as representações sobre a identidade nacional que têm desempenhado um papel importante tanto nas concepções em circulação nos discursos educacionais quanto nas interpretações dos historiadores da educação. 
Em uma obra interessante a respeito das interpretações sobre o Brasil, Custódia Selma Sena (2003) afirmou que, desde o século XIX, a imaginação social brasileira e nossa experiência de brasilidade têm se constituído em torno da imagem dual do país. Dessa maneira, o Brasil tem sido concebido como uma nação cindida em vários binarismos: litoral e sertão, progresso e atraso, moderno e tradicional, país legal e país real, país que se conhece e país que não se conhece etc. De fato, atraso e modernidade recortaram de muitas formas os discursos educacionais proferidos por educadores, intelectuais e políticos de diferentes regiões do país, durante o século XIX e início do século XX.

As disputas pela versão legítima da identidade nacional foram especialmente prolíferas na Primeira República. Compareceram posições diversas, como o nacionalismo de Raul Pompéia e o ufanismo de Afonso Celso e Olavo Bilac (Oliveira, 1990). Outras posições, como a dos intelectuais paulistas, alçaram o bandeirante como modelo exemplar e identificaram a nação ao estado de São Paulo (Ferreira, 2002; Luca, 1999).

Não se deve esquecer ainda, a representação do antagonismo entre sertão e litoral admiravelmente desenvolvida na obra Os Sertóes, de Euclides da Cunha, datada de 1902. A força simbólica dessa representação não pode ser minimizada, como bem observam Candice Souza (1997), Lima (1998) e Oliveira (2000), pois ela ainda mobiliza o pensamento intelectual e político brasileiro na atualidade. $\mathrm{O}$ sertão, visto em seu duplo sentido, como lugar relacionado ao atraso e à barbárie, ou idealizado como espaço da autenticidade nacional cravado no interior do país, é quase sempre cenário de incomensuráveis ausências educacionais. Relacionado também ao mundo rural, para o sertanejo faltam escolas, os professores não se interessam em prover cargos nos confins da pátria, as escolas padecem de condições materiais básicas, como prédio adequado para a atividade escolar, mobiliário e materiais didáticos, e, geralmente, os vencimentos dos professores nessas localidades isoladas são menores.

Todas essas formas de compreensão da nacionalidade exemplificam a noção da nação como comunidade imaginada nos termos propostos por Benedict Anderson (2000). A comparação em âmbito nacional exige, portanto, uma atenção criteriosa sobre as representações e tensões que perpassam os recortes espaciais.

\section{AS CONTRIBUIÇÕES DA EDUCAÇÃO COMPARADA E DA HISTÓRIA COMPARADA}

Os historiadores da educação que se propõem a realizar estudos em perspectiva comparada, seja entre países ou entre regiões do país, enfrentam o problema da fundamentação teórico-metodológica. Os estudos realizados nos últimos anos se têm apoiado em abordagens da educação comparada valendo-se da renovação verificada na área. Porém, mais recentemente se observa a tendência de os estudiosos adotarem abordagens no campo da história comparada, especialmente as chamadas histórias conectadas.

Em se tratando da comparação interna ao país, cabe avaliar a potencialidade de algumas das abordagens que vêm sendo utilizadas pelos pesquisadores e exami- 
nar se é possível estabelecer o diálogo entre elas de maneira que se possa dotar as investigações de maior tessitura teórica.

Da perspectiva da educação comparada, sobressai a abordagem sócio-histórica. Jurgen Schriewer, buscando superar as inconsistências teóricas e metodológicas observadas por ele nos estudos em educação comparada, propôs uma perspectiva analítica que considerasse os objetos de comparação tanto no que se refere a trajetórias de modernização histórico-social como de configurações sócio-culturais, levando em conta também os processos de transferência. De fato, o investimento desse autor tem sido o aprofundamento teórico da comparação vista como método de investigação das ciências sociais (Schriewer; Pedró, 1993; Schriewer, 1995).

Nessa direção, postulou a imperiosa necessidade de os estudiosos distinguirem a comparação como operação mental (obtenção de conhecimento mediante o estabelecimento de relações) da comparação como método científico-social que busca estabelecer relações entre distintos fenômenos e explicá-los com vistas a estabelecer generalizações teóricas. O que distinguiria o método científico comparativo do exercício mental de distinção entre semelhanças e diferenças entre processos ou fenômenos seria a lógica de relacionar relações. Para tanto, o pesquisador deveria pautar-se por uma perspectiva antropológica, adotando o distanciamento e o perspectivismo para a interpretação da alteridade cultural, o que implicaria a adoção de um relativismo cultural e ético que relaciona o outro tendo em vista as suas próprias condições contextuais, buscando entender suas diferenças no que se refere a essas relações (idem, ibidem).

A premissa do estabelecimento de relações entre relações como possibilidade de ampliação e aprofundamento dos estudos para além da identificação das semelhanças e diferenças entre aspectos elegidos para a comparação é valiosa. Contudo, as proposições de Schriewer são desenvolvidas com vista à comparação entre países. Para a análise de modelos de teorização educacional orientada para a reforma educacional, o autor vale-se do conceito de externalização com base na teoria dos sistemas sociais autorreferenciais de Luhmann e Schorr. Esse conceito permite uma compreensão diferenciada sobre relatórios, documentos e análises internacionais sobre educação, pois questiona o modelo de raciocínio internacional presentes nesses documentos. Ele ajuda explicar por que alguns países em certo momento utilizam "exemplos estrangeiros", "Estado-modelo", referências internacionais para justificarem inovações e reformas educativas. A externalização expressa um recurso de reflexão reformadora que atua como mecanismo de autorregulação. Do ponto de vista metodológico, o conceito implica "uma avaliação interpretativa dos dados, estruturas ou questões internacionais, visando à extração de argumentos que sejam 'relevantes' para as políticas e práticas educativas" (Nóvoa; Schriewer, 2000, p. 115).

Essa perspectiva permite analisar a circulação e a apropriação de modelos educacionais vindos ou não do exterior. No entanto, seu viés sociológico interpõe algumas dificuldades. A aproximação com a sociologia demanda o questionamento sobre a articulação dos procedimentos metodológicos dessa disciplina com os praticados na história. Além disso, para além dos pressupostos gerais, ela requer o aprofundamento da teoria da comunicação de Luhmann e Schorr, que é apropriada para a análise de transferências de ideias e modelos, sendo, porém, pouco adequada para outras configurações educacionais. 
Antonio Nóvoa (2000,2009), partindo de Schriewer e da virada linguística, propõe a reconciliação entre história e comparação afirmando que ambas devem levar em conta o tempo e o espaço. $O$ foco da educação comparada deveria ser não os fatos ou as realidades, mas os problemas. Para Nóvoa e Yariv-Mashal (2003), a história deve ser capaz de entender os problemas do presente pela análise da forma como eles se constituíram no passado, localizando-os no tempo e no espaço, por meio de processos de transferência, circulação e apropriação. Visto dessa maneira, significa deslocar a análise exclusiva das fronteiras físicas e inscrevê-la no domínio dos significados.

A perspectiva sócio-histórica, para Nóvoa (2009), reformula o projeto da comparação pela busca de racionalidade científica, atribuindo sentido às práticas observadas dos diferentes atores (individuais, institucionais, políticos) e ao modo como elas reorganizam os espaços em nível nacional e internacional.

Essas indicações gerais são particularmente interessantes por propiciarem o alargamento do repertório metodológico da comparação e por chamarem atenção para os sentidos inscritos nas propostas e políticas educacionais, além de reconhecerem os múltiplos espaços e desdobramentos no tempo.

No campo da história comparada, novas abordagens surgiram nos últimos anos ampliando a abrangência da comparação e reagindo contra as limitações do método comparativo dominante na área proposto por Marc Bloch no início do século XX. ${ }^{6}$ Desde o cáustico libelo desferido por Marcel Detienne (2004) contra a comparação entre sociedades vizinhas e as reações contra práticas comparatistas historiográficas reforçadoras do etnocentrismo, a renovação experimentada pelo campo fez surgirem inúmeras abordagens voltando a atenção para aquilo que Jacques Revel observou como sendo o interesse pelos fenômenos maciços, as longas durações, os espaços vastos (Revel, 2010).

Conforme assinala Maria Lígia Prado (2005), a expressão "histórias conectadas" foi proposta por Sanjay Subrahmanyan, historiador indiano radicado na França, que se contrapôs à visão tradicional da historiografia europeia sobre o mundo asiático. Serge Gruzinski (2001), em defesa dessa abordagem, tem ressaltado a incapacidade de a história comparada perceber as nuances permanecendo

6 Segundo Prado (2005) e Barros (2007), Marc Bloch foi um dos primeiros a sistematizar o método comparativo na história. Para ele, comparar significava afastar das amarras e das limitações dos espaços nacionais. Prado (2005, p. 17-18) sintetiza com propriedade o direcionamento indicado pelo historiador: "Para Bloch, deviam-se escolher dois ou mais fenômenos que parecessem, à primeira vista, apresentar certas analogias entre eles, em um ou vários meios sociais diferentes; em seguida, descrever as curvas de sua evolução, constatar as semelhanças e as diferenças e, na medida do possível, explicá-las à luz da aproximação entre uns e outros. De preferência, ele propunha estudar paralelamente sociedades vizinhas e contemporâneas, sociedades sincrônicas, próximas uma das outras no espaço". Nessa perspectiva, a definição do problema era fundamental, e a busca de explicações indispensável. De acordo com Barros (2007), além do livro Os reis taumaturgos, cuja primeira edição francesa é de 1924, Marc Bloch expôs suas considerações sobre o método comparativo no texto intitulado "Comparaison", publicado no Bulletin du Centre International de Synthèse, em 1930. 
a divisão entre os diversos mundos. Por isso, para esse historiador, as histórias só podem ser múltiplas, e deve-se reconhecer que elas "estão ligadas, conectadas, e que se comunicam entre si” (idem, p. 176). O autor valoriza a figura dos passeurs, compreendidos como mediadores entre os diversos grupos e sociedades e portadores das conexões. Entende-se assim a relevância dada por essa abordagem ao estudo dos indivíduos à medida que permite desvelar o local e o global, rearticulando-os, e compreender os mecanismos de adaptação, de transformação e de invenção implicados nos contatos culturais. A história conectada vale-se ainda do conceito de mestiçagem para explicar o encontro de diferentes etnias, por exemplo, na América, cujos entrelaçamentos resultaram em implicações na produção das técnicas, das artes e das leis (Prado, 2005).

Dessa maneira, tal abordagem busca justamente romper com as limitações das fronteiras nacionais e do etnocentrismo. Como afirma Gruzinski (2001), cabe ao historiador restabelecer as conexões internacionais e intercontinentais que as historiografias nacionais desligaram ou esconderam, bloqueando as suas respectivas fronteiras o que demanda do investigador erudição e maturidade intelectual, revestindo a abordagem de muitas dificuldades e restringindo-a a um pequeno número de estudiosos.

Outra abordagem potencial para a reflexão teórico-metodológica no campo da história comparada é a proposta da história cruzada exposta por Werner e Zimmermann (2003). Para os autores, essa abordagem pertence à família dos procedimentos relacionais que, "tal como a comparação, os estudos de transferência e, mais recentemente, da connected e da shared history, pergunta pelos elos, materializados na esfera social ou simplesmente projetados, entre diferentes formações historicamente constituídas" (idem, p. 90). A abordagem ancora em uma aprofundada discussão sobre história e comparação e alerta para a necessidade de historicização do objeto, das categorias e das relações entre o pesquisador e o objeto.

Nenhuma das escalas de comparação - região, estado-nação, civilização - é rigorosamente unívoca e generalizável. Todas elas são historicamente construídas e situadas, carregadas de conteúdos específicos e difíceis de transpor em quadros diferentes. Quanto à definição do objeto da comparação, os autores lembram que a escolha dos objetos de comparação nunca é neutra, por isso a necessidade de interrogar a historicidade dos objetos. Outra dificuldade reside no corte sincrônico operado pelo comparatista, mesmo quando está investigando transformações no tempo. "Quando se estuda sociedades em contato, frequentemente constatamos que os objetos e as práticas estão não somente em situação de inter-relação, mas ainda se modificam reciprocamente sob o efeito da relação estabelecida" (idem, p. 96).

Para Werner e Zimmermann (idem), os historiadores comparatistas não se podem furtar a uma reflexão sobre a representação de cultura nacional que utilizam. Outra questão problemática a ser observada é a da reciprocidade e a da reversibilidade. Geralmente os estudos de transferência usam a lógica da introdução, difusão e recepção de ideias e modelos. Não obstante, as situações de transferência são mais complexas e as inter-relações são de diferentes tipos. Portanto vale a advertência segundo a qual é apropriado "conceber quadros teóricos e instrumentos metodológicos que permitam abordar fenômenos de interação implicando uma pluralidade de direções e uma multiplicidade de efeitos” (idem, p. 95). 
A ideia de interseção está no princípio da história cruzada e gera uma série de consequências. A primeira delas é a afirmação da abordagem multidimensional rompendo com a perspectiva unidimensional simplificadora e homogeneizadora. A segunda reclama a atenção para as consequências do cruzamento, não só analisar os cruzamentos, mas também suas repercussões. A terceira implica considerar tanto a reciprocidade, isto é, os elementos que são afetados pela situação de relação, quanto a assimetria, ou seja, ter em vista que os elementos não são afetados da mesma forma. Como explicam os autores: "as entidades, pessoas, práticas ou objetos cruzados ou afetados pelo cruzamento não permanecem forçosamente intactos ou idênticos a si mesmos" (idem, p. 96).

Além do cruzamento intrinsecamente ligado ao objeto de pesquisa, a história cruzada, pelo seu caráter relacional, processual e reflexivo postula a necessidade de o pesquisador questionar a constituição do objeto do ponto de vista empírico e epistemológico. Dessa maneira, reivindica a discussão sobre a questão das escalas e o problema das unidades em relação com o local, o regional e o nacional.

Historicizar os objetos e os próprios procedimentos é o horizonte em que se move a história cruzada, cuja afirmação da reflexividade volta-se para as situações de cruzamento e para os atores, submetendo todos os elementos e procedimentos ao escrutínio da reflexão crítica.

A história cruzada compartilha com as histórias conectadas a ideia de "reconectar" histórias separadas, especialmente pelo estancamento produzido pelas historiografias nacionais. No entanto, diferencia-se dessa abordagem por enfatizar a reflexão sobre os procedimentos da comparação e sobre a posição do observador/ historiador que está sempre envolvido no campo de observação.

A grande contribuição dessa abordagem reside justamente no apelo à ação reflexiva em todos os procedimentos de comparação em perspectiva histórica. Os vários questionamentos assinalados, mesmo tendo como horizonte a comparação entre nações, são válidos para a comparação interna a um país, pois permite examinar tanto as conjunturas curtas da ação quanto as condições estruturais de possibilidade da ação, o que implica pensar conjuntamente a mudança e a estabilidade.

Em realidade, todas as abordagens mencionadas neste texto dizem respeito a processos de transferência e contatos culturais entre nações. De fato, os estudos comparados têm reagido contra o isolamento das histórias nacionais postulando a necessidade de restabelecer as conexões internacionais e intercontinentais. É notável, portanto, a ausência de reflexões sistemáticas sobre a comparação interna às regiões nacionais. Consequentemente, para fazer avançar esse tipo de investigação, é imprescindível o investimento teórico-metodológico apropriado. O diálogo com essas abordagens e entre elas constitui um bom ponto de partida.

\section{CONSIDERAÇÕES FINAIS}

No que diz respeito à história da educação no Brasil, o exercício da comparação em âmbito nacional justifica-se precisamente pelo reconhecimento da existência de diferenças na configuração da educação entre os estados e regiões do país. Além da educação, as assimetrias e desigualdades socioculturais e econômicas entre 
os estados valida o questionamento sobre os processos de transferência e contatos culturais, como pressupõem todas as abordagens mencionadas anteriormente, porém é preciso considerar a singularidade da formação histórica da sociedade brasileira. A questão fundamental passa pelo entendimento da natureza das interseções e dos cruzamentos no interior da nação, que, apesar de suas clivagens e diferenças regionais, compartilha inúmeros elementos de identidade coletiva. No investimento comparativo em educação em âmbito nacional, importa compreender como determinados fenômenos, pessoas, modelos educacionais, instituições, processos, práticas ou objetos se inter-relacionam passando de um lugar para outro.

Por exemplo, ao eleger como objeto de comparação a institucionalização da escola primária ou da escola secundária entre os estados brasileiros, o pesquisador se vê compelido a lidar com vários tipos de problemas. $\mathrm{Na}$ análise das representações das finalidades socioculturais e políticas da escola, da circulação de modelos educacionais considerados modernos ou das reformas educacionais, interpõem os processos de transferência, sejam os referencias estrangeiros que justificam os discursos dos políticos e dos educadores e legitimam as iniciativas dos poderes públicos, sejam os referentes internos, isto é, um ou outro estado da federação tomado como referência de modernização e de desenvolvimento educacional. Evidentemente, o estudo dessas interações não pode assumir a nação e os estados como unidades homogêneas e lineares, tampouco subestimar a variedade de direções em que ocorrem os processos de transferência.

No caso, por exemplo, da modernização do ensino primário ocorrida no Brasil na Primeira República, representada pela adoção do método intuitivo, pela implantação dos grupos escolares, pela criação das escolas-modelo, pela renovação dos métodos de ensino da leitura e da escrita, entre outros aspectos, é possível perceber como as trocas e os cruzamentos decorreram de uma multiplicidade de vetores. Concorreram para a disseminação da renovação educacional as visitas de estudos de professores ao exterior comissionadas pelos poderes públicos de diferentes regiões, assim como a experiência de educadores norte-americanos residentes no Brasil, a organização das escolas criadas pelos imigrantes, a tradução de compêndios e manuais, assim como a circulação de relatórios e impressos produzidos no exterior. No âmbito interno, o modelo escolar paulista tornou-se uma referência significativa e vários professores desse estado foram contratados para auxiliar a implantação da reforma do ensino em outras unidades da federação. No entanto as trocas ocorreram também entre outros estados e por referenciais diversos, como atestaram os resultados do projeto temático "Por uma teoria e uma história da escola primária no Brasil: investigações comparadas sobre a escola graduada (1870-1950)" (Araújo; Souza; Pinto, 2012).

Outros exemplos são também emblemáticos, como a disseminação dos princípios da Escola Nova, os projetos de educação rural, a inovação dos métodos de alfabetização e a renovação dos ginásios. Para a compreensão dessas inovações, é indispensável o estudo da circulação de pessoas, objetos, livros e impressos. Mas estudos aprofundados dessa natureza dependem do avanço do conhecimento das histórias regionais/estaduais da educação.

Ainda em relação aos processos de transferência e de contatos culturais, a articulação entre a história nacional e a história dos estados é fundamental. Enquan- 
to república federativa, a relação entre a União e os estados federados no Brasil se impõe como cenário de fundo indispensável para as análises comparadas. Se, por um lado, é também inegável a interdependência dos estados em relação à nação, por outro lado é incontestável as relações entre os estados. No entanto, a relação entre os estados não pode ser pensada da mesma maneira que a comparação entre nações, muitas vezes assumidas como entidades monolíticas. Não obstante, é preciso também reconhecer as diferenças regionais no Brasil que não são apenas econômicas, mas também socioculturais. Então como tratar essa interdependência e essas diferenças? Como explicar simultaneamente os traços comuns adquiridos na organização do ensino em cada estado e as peculiaridades e diferenças educacionais presentes nas diversas unidades da federação?

Os princípios gerais das histórias conectadas podem ser úteis ao advertir para a multiplicidade das histórias e suas ligações servindo como sinalizadores da complexidade da interdependência entre as histórias regionais do país. Outra indicação válida é a do estudo dos mediadores das conexões, o que implica em investigações aprofundadas sobre a circulação do pensamento educacional e sobre a atuação de determinados educadores levando em conta a recepção e a apropriação dos modelos pedagógicos nos sistemas estaduais de ensino. Mas, como no estudo da comparação entre nações, o estudo das conexões em âmbito nacional exige acompanhar trajetórias múltiplas de sujeitos, objetos e impressos em situações localizadas, consistindo em um exercício de investigação bastante minucioso que exige o conhecimento aprofundado das histórias regionais.

O cruzamento e a interseção pressupostos nos contatos culturais são também enfatizados na abordagem da história cruzada. No entanto, essa abordagem chama atenção para os efeitos e as repercussões dos cruzamentos, além das resistências, inércias e transformações deles decorrentes, lembrando que entidades, pessoas, práticas ou objetos que estão entrelaçados ou afetados pelo processo de cruzamento não necessariamente permanecem intactos em sua primeira forma. Essa indicação é particularmente fértil para a análise comparada das reformas educacionais levadas a termo pelos estados em diferentes períodos históricos, especialmente para analisar a circulação dos modelos educacionais e as formas diferenciadas de sua apropriação.

Entre as várias indicações teórico-metodológicas oferecidas pela abordagem da história cruzada, vale destacar neste texto a necessidade de historicizar os objetos de pesquisa, as categorias de análise e a relação do pesquisador com o objeto de pesquisa. Esse procedimento metodológico é salutar, pois permite manter uma reflexão cautelar no exercício da comparação em âmbito nacional evitando a naturalização dos objetos de pesquisa. Alguns objetos que têm sido alvo de investigações comparadas no país, como a institucionalização dos grupos escolares, as diferentes modalidades de escolas primárias, a relação entre educação, republicanismo e cidadania nos discursos governamentais, entre outros, são construções históricas cujos sentidos é necessário considerar. O mesmo é válido para as categorias de análise, para que não sejam assumidas como um pressuposto, mas como uma ferramenta de reflexão do processo de investigação.

No que diz respeito à relação entre pesquisador e objeto de pesquisa, o problema perpassa a especialização cada vez maior dos relatos históricos em âmbito 
regional/estadual vigente no país. Se por um lado é indispensável a verticalização do conhecimento da história da educação de cada estado, por outro lado, esse excesso de especialização dificulta o trânsito para a análise comparada entre os estados. Equipes de pesquisa envolvendo historiadores da educação de diferentes estados são imprescindíveis para intensificar o diálogo e qualificar a discussão dos dados, pois permite aproveitar a experiência e o domínio do conhecimento que os pesquisadores possuem em relação à história da educação regional. Não obstante, cruzar as fronteiras regionais requer ultrapassar também as barreiras da especialização e do acesso às fontes de pesquisa.

Por último, cabe assinalar a problemática questão do alcance da comparação entre a afirmação da diferença e as (im)possibilidades de generalizações. A busca de relações generalizáveis foi um dos objetivos perseguidos pela educação comparada até pouco tempo atrás, porém o problema da alteridade cultural pôs em questão os males do etnocentrismo, e a virada culturalista nas ciências sociais ocorridas nas últimas décadas passou a enfatizar a especificidade e o caráter irredutível do local. Consequentemente, certo relativismo tornou-se indispensável na comparação exigindo um olhar contrastante sobre o funcionamento diferenciado das sociedades e das culturas.

Se atualmente as abordagens comparatistas abdicaram do estabelecimento de relações generalizáveis, o que justificaria o investimento comparativo? Qual a contribuição dos estudos comparados para a superação da fragmentação do conhecimento e da pesquisa verificados no campo da história e da história da educação? Essa certamente não é uma resposta fácil, e um melhor equacionamento da questão dependerá muito da consolidação dos estudos históricos comparados. Contudo, não se pode perder de vista a busca de compreensão mais ampliada implícita no método comparativo, assim como o uso da generalização como unidade lógico-metodológica. O que deve ser questionado é a generalização apressada, as interpretações generalizantes desancoradas de bases empíricas e fundamentadas na história de um estado ou de uma região do país. A reação contra a pretensão de se construir uma história única e unificada do país não impede o reconhecimento de semelhanças e processos comuns contrastados permanentemente com as configurações locais com suas tonalidades específicas.

Por ora, as poucas investigações realizadas na área da história da educação no Brasil em perspectiva comparada em âmbito nacional têm atestado a fertilidade desse investimento. $\mathrm{O}$ olhar para os lados tem enriquecido o conhecimento das histórias regionais e ampliado o reconhecimento de aspectos comuns, aproximações, vizinhanças e distanciamentos. A consideração da diversidade regional tem se imposto como perspectiva analítica, o que significa lidar com os referentes dando a eles novos pesos. Não é demais reiterar a contribuição dos estudos comparados para a redefinição dos horizontes das práticas e das interpretações da história da educação no Brasil requerendo que essa história seja mais respeitosa com a diversidade e mais exigente com as explicações de determinados fenômenos e processos. 


\section{REFERÊNCIAS}

Alves, C. A escrita da história da educação na pós-graduação no Rio de Janeiro (1972-2001). In: Gondra, J. G. (Org.). Pesquisa em história da educação no Brasil. Rio de Janeiro: DP\&A, 2005. p. 113-155.

Anderson, B. Imagined communities. London: Verso, 2000.

Araújo, J. C. S.; Freitas, A. G. B.; Lopes, A. P. C. (Orgs.). As escolas normais no Brasil: do Império à República. Campinas: Alínea, 2008.

.; Souza, R. F.; Pinto, R. N. (Orgs.). Escola primária na Primeira República (1889-1930): subsídios para uma história comparada. Araraquara: Junqueira \& Marin, 2012.

Araújo, M. M. (Org.). História(s) comparada(s) da educação. Brasília: Liber Livro, 2009. BArros, J. A. História comparada: um novo modo de ver e fazer a história. Revista de História Comparada, Rio de Janeiro: UFRJ, v. 1, n. 1, p. 1-30, jun. 2007. Disponível em: <http://www.hcomparada.historia.ufrj.br/revistahc/artigos/volume001_Num001_ artigo001.pdf $>$. Acesso em: 23 out. 2012.

Bittencourt, C. M. F. (Org.). Em foco: história, produção e livro didático. Educação e Pesquisa, São Paulo: USP, v. 30, n. 3, p. 471-473, set./dez. 2004.

B Lосн, M. "Comparaison". Bulletin du Centre International de Synthèse, Paris: La Renaissance du Livre, n. 9, p. 17-35, jun. 1930.

Bontempi Junior, B. A historiografia da educação em Portugal e no Brasil: convergências e desafios. Contemporaneidade e Educação, Rio de Janeiro: Instituto de Estudos da Cultura e Educação Continuada, ano V, n. 7, p. 34-50, 2000.

Brasil. Lei n. 16, de 12 de agosto de 1834. Faz algumas alterações e adições à Constituição Política do Império, nos termos da lei de 12 de outubro de 1832. Coleção de Leis do Império do Brasil, 1834.v. 1, p. 15. Disponível em: <http://www2.camara.leg.br/ legin/fed/lei/1824-1899/lei-16-12-agosto-1834-532609-publicacaooriginal-14881-pl. html>. Acesso em: 21 fev. 2013.

Campello Souza, M. C. Federalismo no Brasil: aspectos político-institucionais (1930-1964). Revista Brasileira de Ciências Sociais, São Paulo: ANPOCS, v. 21, n. 61, p. 7-40, jun. 2006.

Carvalho, M. M. C.; Pintassilgo, J. (Orgs.). Modelos culturais, saberes pedagógicos, instituiçôes educacionais. São Paulo: EDUSP, 2011.

Castro, C. A. (Org.). Cultura material escolar: a escola e seus artefatos (MA, SP, PR, SC e RS, 1870-1925). 1. ed. São Luís: EDUFMA; Café e Lápis, 2011.

Catani, D. Distâncias, vizinhanças, relações: comentários sobre os estudos sócio-histórico-comparados em educação. In: NóvoA, A.; Schriewer, J. (Eds.). A difusão mundial da escola. Lisboa: Educa, 2000. p. 143-150.

Escrever e comparar-se, mapear e apropriar-se: questões da pesquisa em história da educação. In: Gatti Junior, D.; Pintassilgo, J. (Orgs.). Percursos e desafios da pesquisa e do ensino de história da educação. Uberlândia: EDUFU, 2007. p. 165-182. 
Costa Rico, A. Territorios, identidades y gentes: para una revisión de la historia de la educación em España. Historia de la Educación, Salamanca: Universidad de Salamanca, n. 25, p. 105-129, 2006.

Detienne, M. Comparar o incomparável. São Paulo: Ideias \& Letras, 2004.

Ferreira, A. C. A epopeia bandeirante: letrados, instituições, invenção histórica (1870-1940). São Paulo: Editora UNESP, 2002.

Galvão, A. M.; Moraes, D. Z.; Gondra, J. G.; Biccas, M. S. Difusão, apropriação e produção do saber histórico. A Revista Brasileira de História da Educação (2001-2007). Revista Brasileira de História da Educação, São Paulo: SBHE, n. 16, p. 171-234, jan./abr. 2008.

Gomes, P. C. C. O conceito de região e sua discussão. In: Castro, I. E.; Gomes, P. C. C.; CorrêA, R. L. Geografia: conceitos e temas. 11. ed. Rio de Janeiro: Bertrand Brasil, 2008. p. 49-73.

Gondra, J. G.; Silva, J. C. S. (Orgs.). História da educação na América Latina: ensinar \& escrever. Rio de Janeiro: EDUERJ, 2011.

GRUZINSKi, S. Os mundos misturados da monarquia católica e outras connected histories. Topoi, Rio de Janeiro: UFRJ, v. 2, n. 2, p. 175-195, mar. 2001.

Lencioni, S. Região e geografia. São Paulo: EDUSP, 2003.

Lima, N. T. Um sertão chamado Brasil: intelectuais e representação geográfica da identidade nacional. Rio de Janeiro: Revan; IUPERJ; UCAM, 1998.

LucA, T. R. A Revista do Brasil: um diagnóstico para a (N)ação. São Paulo: Editora UNESP, 1999.

Luhmann, N.; Schorr, K.-E. Problems of reflection in the system of education. Tradução de Rebecca A. Neuwirth. Munster, New York: Waxmann, 2000.

Miguel, M. E. B.; Vidal, D. G.; Araújo,J. C. S. Reformas educacionais: as manifestações da Escola Nova no Brasil (1920-1946). Campinas: Autores Associados; Uberlândia: EDUFU, 2011. (coleção Memória da Educação)

Neves, D. S. S. Razões de Estado: as reformas da instrução pública em Mato Grosso, Minas Gerais e na Corte Imperial (1851-1859). 2009. Tese (Doutorado em Educação) Universidade Estadual do Rio de Janeiro, Rio de Janeiro, 2009.

NóvoA, A.; Schriewer, J. (Eds.). A difusão mundial da escola. Lisboa: Educa, 2000.

.Tempos da escola no espaço Portugal-Brasil-Moçambique. Dez digressões sobre um programa de investigação. In: .; Schriewer, J. (Eds.). A difusão mundial da escola. Lisboa: Educa, 2000. p. 143-150.

. Modelos de análise de educação comparada: o campo e o mapa. In: SouzA, D. B.; Martínez, S. A. (Orgs.). Educação comparada: rotas de além-mar. São Paulo:Xamã, 2009. p. 23-62.

.; YARIV-Mashal, T. Comparative research in education: a mode of governance or a historical journey? Comparative Education, Chicago: The University of Chicago Press, v. 39, n. 4, p. 423-438, nov. 2003.

Nunes, C. Historiografia comparada da Escola Nova: algumas questões. Revista da Faculdade de Educação, São Paulo: USP, v. 24, n. 1, p. 105-125, jan./jun. 1998. 
História da educação e comparação: algumas interrogações. In: SocıEdADE Brasileira de História da Educação (Org.). Educação no Brasil: história e historiografia. Campinas: Autores Associados, 2001. p. 53-71.

Oliveira, L. L. A questão nacional na Primeira República. São Paulo: Brasiliense, 1990. Americanos: representações da identidade nacional no Brasil e nos EUA. Belo Horizonte: Editora UFMG, 2000.

Prado, M. L. C. Repensando a história comparada da América Latina. Revista de História, São Paulo: USP, n. 153, p. 11-33, 2005.

Revel, J. Microanálise e construção do social. In: (Org.). Jogos de escala: a experiência da microanálise. Rio de Janeiro: Editora FGV,1996. p. 15-38.

Micro-história, macro-história: o que as variações de escala ajudam a pensar em um mundo globalizado. Revista Brasileira de Educação, Rio de Janeiro: ANPEd; Campinas: Autores Associados, v. 15, n. 45, p. 434-444, set./dez. 2010.

Saviani, D. História comparada da educação: algumas aproximações. História da Educação, Pelotas: UFPel, v. 5, n. 10, p. 5-15, 2001.

Schriewer, J.; Pedró, F. (Eds.). Manual de educación comparada. Teorías, investigaciones, perspectivas. Barcelona: PPU, 1993. v. II.

. Sistema mundial e inter-relacionamento de redes: a internacionalização da educação e o papel da pesquisa comparativa. Revista Brasileira de Estudos Pedagógicos, Brasília: INEP, v. 76, n. 182-183, p. 241-304, jan./ago. 1995.

Estados-modelo e sociedade de referência: externalização em processos de modernização. In: NóvoA, A.; Schriewer, J. A difusão mundial da escola. Lisboa: Educa, 2000. p. 103-140. (Educa História, 4)

Aceitando os desafios da complexidade: metodologia da educação comparada em transição. In: SouzA, D. B.; Martínez, S. A. (Orgs.). Educação comparada: rotas de além-mar. São Paulo: Xamã, 2009.p. 63-92.

SENA, C. S. Interpretações dualísticas do Brasil. Goiânia: EDUFG, 2003.

Souza, C. V.A pátria geográfica: sertão e litoral no pensamento social brasileiro. Goiânia: EBEU, 1997.

Souza, D. B.; Martínez, S. A. (Orgs.). Educação comparada: rotas de além-mar. São Paulo: Xamã, 2009. p. 237-258.

Souza, R. F.; Silva, V. L. G.; SÁ, E. F. (Orgs.). Por uma teoria e uma história da escola primária no Brasil: investigações comparadas sobre a escola graduada (1870-1930). Cuiabá: EdUFMT, 2013.

Toledo, M. R.A.; Carvalho, M. M. C. Print capitalism, new school and circulation of reading models. A Brazilian collection at the Primary Education Museum-Library in Portugal (1931-1950). Paedagogica Historica, London: Routledge, v. 47, p. 639-656, 2011. Veiga, C. G. A escola e a República: o estadual e o nacional nas políticas educacionais. Revista Brasileira de História da Educação, Campinas: SBHE, v. 11, n. 1 (25), p. 143-178, jan./abr. 2011.

VIdAL, D. G.; Gvi RTz, S. O ensino da escrita e a conformação da modernidade escolar: Brasil e Argentina, 1880-1940. Revista Brasileira de Educação, Rio de Janeiro: ANPEd; Campinas: Autores Associados, n. 8, p. 13-30, 1998. 
. (Org.). Grupos escolares: cultura escolar primária e escolarização da infância no Brasil (1893-1971). Campinas: Mercado de Letras, 2006.

.; Ascolani, A. (Orgs.). Reformas educativas no Brasil e na Argentina. Ensaios de história comparada da educação (1820-2000). São Paulo: Cortez, 2009.

.; Vicentini, P. P.; Silva, K. N.; Silva, J. C. S. História da educação no estado de São Paulo: a configuração do campo e a produção atual (1943-2003). In: GondRA,J. G. (Org.). Pesquisa em história da educação no Brasil. Rio de Janeiro: DP\&A, 2005.p.157-219.

WARDE, M.J.Americanismo e educação: um ensaio no espelho. São Paulo em Perspectiva, São Paulo: SEADE, v. 14, n. 2, p. 37-47, 2000.

WerLe, F. O. C. (Org.). Educação rural em perspectiva internacional. Instituições, práticas e formação do profesor. Ijuí: Editora Unijuí, 2007.

Werner, M.; Zimmermann, B. Pensar a história cruzada: entre experiência e reflexividade. Textos de História. Revista do Programa de Pós-Graduação em História da UnB, Brasília: UnB, v. 11, n. 1-2, p. 89-127, 2003.

XAvier, L. Particularidades de um campo disciplinar em consolidação: balanço do I CBHE. In: Sociedade Brasileira de História da Educação. Educação no Brasil. Campinas: Autores Associados; SBHE, 2001. p. 217-230.

\section{SOBRE A AUTORA}

Rosa Fátima de Souza é doutora em educação pela Universidade de São Paulo (USP). Professora da Universidade Estadual Paulista (UNESP). E-mail: rosa@fclar.unesp.br 